\title{
Experiências com o ensino híbrido a partir de seminários virtuais assíncronos: contribuições para um cenário de mudanças
}

\author{
Viviane Patrícia Pereira Félix ${ }^{1}$ \\ Ivanderson Pereira da Silva ${ }^{2}$
}

\begin{abstract}
RESUMO
O Ensino de Ciências da Saúde em nível Superior ainda percebe, de forma predominante, seus aprendizes como receptores de informações. Diante desse cenário, foram propostos seminários virtuais assíncronos de Histologia, a fim de promover o protagonismo dos estudantes do $1^{\circ}$ ano do Curso de Enfermagem de uma Universidade Pública de Alagoas. O presente estudo teve por objetivos: compreender as demandas formativas que se apresentam na sociedade em face do contexto da cibercultura; explorar as potencialidades dos ambientes virtuais de aprendizagem para o desenvolvimento de experiências formativas no contexto do Ensino de Saúde; e analisar os limites e possibilidades dos seminários virtuais assíncronos para o ensino de Histologia. A coleta e análise dos dados se deu, respectivamente, por meio de Grupo Focal e Análise de Conteúdo. Constatou-se que esse tipo de estratégia favorece o protagonismo discente.
\end{abstract}

PALAVRAS-CHAVE: Ensino Híbrido. Histologia. Educação Online. Seminários Virtuais.

Experiences with hybrid teaching from asynchronous virtual seminars: contributions to a changing scenario

\footnotetext{
${ }^{1}$ Mestra em Ensino de Ciências e Matemática. Universidade Estadual de Ciências da Saúde de Alagoas, Maceió, Alagoas, Brasil. Orcid: https://orcid.org/0000-0002-0118-373X. E-mail: vivianeppf.bio@ gmail.com.

2 Doutor em Educação.Universidade Federal de Alagoas, Arapiraca, Alagoas, Brasil. Orcid: https://orcid.org/00000001-9565-8785. E-mail: ivanderson@gmail.com.
} 


\begin{abstract}
The teaching of Health Sciences at a Higher Level still predominantly perceives its apprentices as recipients of information. In view of this scenario, asynchronous virtual seminars on histology were proposed in order to promote the role of students in the 1st year of the Nursing Course at a Public University in Alagoas. The present study had as objectives: to understand the formative demands that are presented in the society in face of the cyberculture context; explore the potential of virtual learning environments for the development of training experiences in the context of Health Education; and to analyze the limits and possibilities of asynchronous virtual seminars for the teaching of Histology. Data collection and analysis took place, respectively, through Focus Group and Content Analysis. It was found that this type of strategy favors student protagonism.
\end{abstract}

KEYWORDS: Hybrid Teaching. Histology. Online Education. Virtual Seminars.

Experiencias de enseñanza híbrida a partir de seminarios virtuales asincrónicos: aportes a un escenario cambiante

\title{
RESUMEN
}

La enseñanza de las Ciencias de la Salud en un Nivel Superior todavía percibe predominantemente a sus aprendices como receptores de información. Ante este escenario, se propusieron seminarios virtuales asincrónicos sobre Histología con el fin de promover el protagonismo de los estudiantes de 1er año del Curso de Enfermería en una Universidad Pública de Alagoas. El presente estudio tuvo como objetivos: comprender las demandas formativas que se presentan en la sociedad frente al contexto de la cibercultura; explorar el potencial de los entornos virtuales de aprendizaje para el desarrollo de experiencias formativas en el contexto de la Educación para la Salud; y analizar los límites y posibilidades de los seminarios virtuales asincrónicos para la enseñanza de la Histología. La recolección y análisis de datos se llevó a cabo, respectivamente, a través de Focus Group y Content Analysis. Se encontró que este tipo de estrategia favorece el protagonismo de los estudiantes.

PALABRAS CLAVE: Enseñanza híbrida. Histología. Educación en línea. Seminarios virtuales.

$$
* * *
$$




\section{Introdução}

O Ensino Superior ainda é marcado, predominantemente, pelo protagonismo docente, sendo os aprendizes, no caso em questão do Ensino de Ciências da Saúde, percebidos como receptores de informações técnicocientíficas sobre doenças e tratamentos (CECCIM; FEUERWERKER, 2004). Entretanto, “a sociedade atual sugere que o estudante seja alguém que busque construir seu conhecimento, alguém flexível, que saiba lidar com as necessidades de maneira criativa e manifeste vontade de aprender, pesquisar e saber" (AMEM; NUNES 2006, p. 172).

Diante dessa realidade, propomos e aplicamos junto aos estudantes do $1^{\circ}$ ano do curso de Enfermagem de uma Instituição de Ensino Superior (IES), seminários virtuais assíncronos de Histologia no Ambiente Virtual de Aprendizagem (AVA) Moodle (Modular Object Oriented Dynamic Learning Environment).

Preferimos trabalhar com seminários porque, além dos discentes estarem familiarizados com essa estratégia de ensino socializado, esse tipo de estratéfia favorece a mobilização do "conhecimento para pesquisar (estudando e lendo), em seguida se discute por meio de base teórica e prática, construindo sínteses" (ANASTASIOU; ALVES, 2006, p. 90). Por sua vez, desenvolver o fazer pedagógico no ambiente virtual é construir redes e não rotas, uma vez que o educador deixa de se posicionar como detentor do monopólio do saber, passando a dispor teias (SILVA, 2006).

Em face desse quadro, o presente estudo teve por objetivos: compreender as demandas formativas que se apresentam na sociedade em face do contexto da cibercultura; explorar as potencialidades dos ambientes virtuais de aprendizagem para o desenvolvimento de experiências formativas no contexto do Ensino de Saúde; e analisar os limites e possibilidades dos seminários virtuais assíncronos para o ensino de Histologia. 
Trata-se de um estudo de caso, de natureza qualitativa (EISENHARDT, 1989; YIN, 2009; BRANSKI et al, 2010). Os resultados dessa investigação foram organizados em mais três seções que, além de trazerem uma proposta de currículo flexível integrado ao uso das Tecnologias Digitais da Informação e Comunicação (TDIC), permitem uma reflexão acerca da importância de compartilhar o protagonismo do processo de ensino e aprendizagem com os estudantes.

\section{A necessidade de arranjos curriculares flexíveis}

$\mathrm{Na}$ era da informação, se faz necessário construir novos modelos curriculares, haja vista que a geração Homo zappiens, também conhecida como geração Y e Z, ou, ainda, pós-internet, que corresponde aos indivíduos nascidos após a década de 1980, encara a escola mais como um ambiente de encontro com os amigos do que como um lugar de aprendizagem (LÉVY, 2010; VENN; VRAKKING, 2009).

Tal fato acontece porque como esses indivíduos habituaram-se a usar jogos eletrônicos, a produzir, interagir e compartilhar informações por meio de redes sociais e a utilizar dispositivos móveis, tanto demandam da inserção das tecnologias digitais em suas práticas educativas como, provavelmente, sentem a não-presença delas nos processos educativos (LARA; QUARTIERO, 2009).

Em virtude desses fatores, as instituições de ensino, que se constituem como espaços de desenvolvimento de práticas sociais, são inseridas na rede e desafiadas a conviver com as transformações que as tecnologias e mídias digitais provocam na sociedade e na cultura, uma vez que elas são trazidas para dentro das salas de aula pelos alunos, cidadãos pouco orientados sobre a forma de se relacionar educacionalmente com esses artefatos culturais que permeiam suas práticas cotidianas (ALMEIDA; SILVA, 2011). 
Sendo assim, instituições educacionais atentas às mudanças impostas pela cibercultura (relação desenvolvida pela sociedade contemporânea entre tecnologias digitais e a vida social), estão revendo seus currículos, suas metodologias, seus tempos e espaços e escolhendo fundamentalmente dois caminhos: 1. Modelos de mudanças progressivas, considerados mais suaves, uma vez que mantêm o modelo curricular disciplinar, mas priorizam o envolvimento do aluno com metodologias ativas como, por exemplo, o ensino híbrido ou blended; ou 2. Modelos disruptivos, considerados inovadores e de mudanças profundas, ao passo que propõem modelos sem disciplinas, que redesenham o projeto, os espaços físicos, as metodologias baseadas em atividades, desafios, problemas, jogos e onde cada estudante aprende no seu próprio ritmo, de acordo com suas necessidades e com os outros em grupos, com supervisão de professores orientadores (MORAN, 2015).

Nesse estudo de caso, analisamos a aplicação de um modelo de mudança progressiva, que priorizou o envolvimento do estudante com uma metodologia ativa: o ensino híbrido. Este tipo de abordagem, está despontando como uma inovação sustentada em relação à sala de aula tradicional uma vez que aponta contributos para melhorar o que já existe (CHRISTENSEN; HORN; STAKER, 2013; HORN et al., 2016)

O blended learning é um conceito de educação que faz uso de diversos métodos para facilitar o aprendizado, garantir a colaboração entre os estudantes e permitir a criação e troca de conhecimentos (SPINARDI; BOTH, 2017). Por ser integrado a tecnologia, promove a adaptabilidade ou personalização do ensino e a autonomia dos sujeitos envolvidos com o processo de ensino, ou seja, propicia a corresponsabilização, principalmente entre alunos e professores, pela qualidade do ensino oferecido e pela aprendizagem desenvolvida (BARBOSA, 2016).

Com efeito, conforme destaca Oliveira, Maciel e Silva (2018), na educação híbrida o professor é fundamental na organização e na condução de todo o processo, mediando o conhecimento, valorizando a autonomia de 
seus alunos, haja vista que o acesso à informação na sociedade cibercultural se faz de modo rápido, a qualquer hora e em qualquer lugar. Ademais, o processo de feedback precisa ser o motor de reorientação da prática das aulas no blended learning, ou seja, todos os dados utilizados para verificar a aprendizagem precisam reagir aos resultados (RODRIGUES, 2015). Por isso, nesse formato de ensino, a avaliação deixa de ser um processo classificatório, passando, então, a fazer parte de todo o processo de ensino-aprendizagem (SPINARDI; BOTH, 2017).

$\mathrm{Na}$ seção seguinte apresentamos, a metodologia de intervenção/investigação utilizada.

\section{Descrição do caso de uma experiência com o Ensino Híbrido}

A experiência híbrida sucintamente apresentada nesta seção (Quadro 1), ou seja, os seminários virtuais assíncronos de Histologia, que corresponde a um recorte de uma dissertação de mestrado profissional em ensino (FÉLIX, 2020) e que só foi aplicada a partir do parecer favorável $\left(\mathrm{n}^{\circ}\right.$. 3.455.779) do Comitê de Ética, versou sobre cinco doenças do Tecido Conjuntivo: Dermatomiosite/Polimiosite; Lúpus Eritematoso Sistêmico (LES); Esclerose Sistêmica; Doença Mista do Tecido Conjuntivo (DMTC) ou Síndrome de Sharp; e Osteogênese Imperfeita, discutidas pelos alunos do $1^{\circ}$ ano do curso de Enfermagem de uma universidade de Alagoas, na interface Fórum do Moodle, que se tornou a sala de aula virtual deles durante cinco semanas consecutivas.

Quadro 1: Ensino híbrido de histologia baseado em seminários virtuais assíncronos

\begin{tabular}{|c|l|l|l|}
\hline $\begin{array}{c}\text { Data / } \\
\text { Período }\end{array}$ & \multicolumn{1}{|c|}{ Atividade } & Modalidade & \multicolumn{1}{|c|}{ Descrição } \\
\hline $\begin{array}{c}\text { 19/02/2019 } \\
\text { a } \\
04 / 06 / 2019\end{array}$ & $\begin{array}{l}\text { Explanação dos } \\
\text { conteúdos de } \\
\text { Histologia }\end{array}$ & Presencial & $\begin{array}{l}\text { Os conteúdos de Histologia foram ministrados } \\
\text { antecipadamente aos seminários virtuais } \\
\text { assíncronos como forma de facilitar o } \\
\text { entendimento dos alunos dos temas que eles } \\
\text { iriam desenvolver. }\end{array}$ \\
\hline
\end{tabular}




\begin{tabular}{|c|c|c|c|}
\hline $14 / 05 / 2019$ & $\begin{array}{l}\text { Apresentação } \\
\text { da proposta de } \\
\text { ensino híbrido } \\
\text { de Histologia ao } \\
\text { gestor da } \\
\text { universidade } \\
\end{array}$ & Presencial & $\begin{array}{l}\text { Apresentação da proposta de ensino } \\
\text { híbrido de Histologia ao gestor da } \\
\text { universidade bem como solicitação de } \\
\text { autorização para execução da mesma no } 1^{\circ} \\
\text { ano do curso de Enfermagem da } \\
\text { instituição. }\end{array}$ \\
\hline $15 / 05 / 2019$ & $\begin{array}{l}\text { Solicitação de } \\
\text { abertura da } \\
\text { sala de aula } \\
\text { virtual de } \\
\text { Histologia do } 1^{\circ} \\
\text { ano do curso de } \\
\text { Enfermagem } \\
\end{array}$ & Presencial & $\begin{array}{l}\text { Foi solicitada a abertura da sala de aula } \\
\text { virtual de Histologia do } 1^{\circ} \text { ano do curso de } \\
\text { Enfermagem a uma das administradoras } \\
\text { do Moodle na instituição para execução da } \\
\text { proposta de ensino híbrido na referida } \\
\text { disciplina. }\end{array}$ \\
\hline $25 / 06 / 2019$ & $\begin{array}{l}\text { Sondagem sobre } \\
\text { a aplicação de } \\
\text { uma proposta } \\
\text { de ensino } \\
\text { híbrido junto } \\
\text { aos alunos }\end{array}$ & Presencial & $\begin{array}{l}\text { Foi conversado junto aos alunos do } 1^{\circ} \text { ano } \\
\text { do curso de Enfermagem da instituição, } \\
\text { antes da explanação do primeiro assunto } \\
\text { do bloco de Biologia Celular e Molecular } \\
\text { (BCM), sobre a intenção de desenvolver } \\
\text { uma atividade híbrida com eles, fruto de } \\
\text { uma pesquisa de mestrado, como } \\
\text { complemento da nota do bimestre da } \\
\text { disciplina. Eles sugeriram que essa } \\
\text { atividade valesse uma pontuação extra } \\
\text { média. Ficou combinado que essa } \\
\text { contraproposta seria participada a outra } \\
\text { professora da disciplina. }\end{array}$ \\
\hline 02/07/2019 & $\begin{array}{l}\text { Apresentação } \\
\text { da proposta de } \\
\text { ensino híbrido a } \\
\text { outra professora } \\
\text { de Histologia }\end{array}$ & Presencial & $\begin{array}{l}\text { Foi participado a outra professora de } \\
\text { Histologia que também compartilha a } \\
\text { disciplina, antes da aplicação da prova de } \\
\text { reavaliação do } 2^{\circ} \text { bimestre, a proposta de } \\
\text { ensino híbrido que se pretendia aplicar junto } \\
\text { aos alunos do } 1^{\circ} \text { ano do curso de } \\
\text { Enfermagem da instituição no } 3 \text { bimestre. } \\
\text { Na sequência, foi participado a ela o } \\
\text { resultado da sondagem com os estudantes, } \\
\text { ou seja, a contraproposta. A mesma não se } \\
\text { opôs, desde que a pontuação extra (2,0 } \\
\text { pontos) fizesse parte apenas do bloco de } \\
\text { BCM. }\end{array}$ \\
\hline 02/07/2019 & $\begin{array}{l}\text { Divulgação do } \\
\text { resultado da } \\
\text { contraproposta }\end{array}$ & Presencial & $\begin{array}{l}\text { Antes da aplicação da prova de reavaliação da } \\
\text { disciplina, foi participado aos alunos que a } \\
\text { proposta de ensino híbrido que seria aplicada } \\
\text { junto a eles no } 3^{\circ} \text { bimestre, entraria como } \\
\text { uma pontuação extra. Na sequência, foi } \\
\text { solicitado a representante da turma que } \\
\text { enviasse pelo whatsapp a lista dos estudantes } \\
\text { distribuídos em cinco grupos. }\end{array}$ \\
\hline 06/07/2019 & $\begin{array}{l}\text { Sorteio dos } \\
\text { temas dos } \\
\text { seminários } \\
\text { virtuais } \\
\text { assíncronos }\end{array}$ & A distância & $\begin{array}{l}\text { Em virtude do recesso acadêmico, a ser } \\
\text { oficialmente iniciado no dia 08/07/2019, } \\
\text { realizou-se os sorteios dos temas dos } \\
\text { seminários virtuais assíncronos via } \\
\text { Smartphone, por videochamada, com a } \\
\text { representante da turma. }\end{array}$ \\
\hline
\end{tabular}




\begin{tabular}{|c|c|c|c|}
\hline $15 / 07 / 2019$ & $\begin{array}{l}\text { Convite para } \\
\text { conhecer a sala } \\
\text { de aula virtual }\end{array}$ & A distância & $\begin{array}{l}\text { Os alunos foram convidados, via e-mail, a } \\
\text { conhecer a sala de aula virtual, palco dos } \\
\text { seminários virtuais. }\end{array}$ \\
\hline $30 / 07 / 2019$ & $\begin{array}{l}\text { Oficina para os } \\
\text { seminários } \\
\text { virtuais } \\
\text { assíncronos }\end{array}$ & Presencial & $\begin{array}{l}\text { Na sala de aula física foi realizada a oficina } \\
\text { preparatória para os seminários virtuais } \\
\text { assíncronos. Nessa oficina foi explicado aos } \\
\text { alunos o que eles deveriam fazer antes e } \\
\text { durante as apresentações no Moodle, ou seja, } \\
\text { discutiu-se, por meio de exemplos, os } \\
\text { requisitos do desenho didático online, } \\
\text { material didático online, avaliação online e } \\
\text { docência online. }\end{array}$ \\
\hline 02/08/2019 & $\begin{array}{l}\text { Disponibilização } \\
\text { dos slides da } \\
\text { oficina }\end{array}$ & A distância & $\begin{array}{l}\text { Os slides da oficina foram disponibilizados } \\
\text { na sala de aula virtual. Os alunos foram } \\
\text { informados disso via e-mail. }\end{array}$ \\
\hline 05/08/2019 & $\begin{array}{l}\text { Disponibilização } \\
\text { de tutorial para } \\
\text { complementar a } \\
\text { oficina }\end{array}$ & A distância & $\begin{array}{l}\text { Foi disponibilizado, via e-mail e na sala de } \\
\text { aula virtual, um tutorial, uma vez que na } \\
\text { hora de desenvolver a parte prática da } \\
\text { oficina faltou conectividade. }\end{array}$ \\
\hline 06/08/2019 & $\begin{array}{l}\text { Explanação de } \\
\text { assuntos do } 3^{\circ} \\
\text { bimestre e } \\
\text { esclarecimento } \\
\text { das dúvidas do } \\
\text { Grupo } 1 \text { dos } \\
\text { seminários }\end{array}$ & Presencial & $\begin{array}{l}\text { Explanações } \\
\text { Macromoleculares e e Síntese de de } \\
\text { Macromoléculas e ao final da aula } \\
\text { esclarecimento das dúvidas técnicas e } \\
\text { pedagógicas do grupo 1, que iria abordar } \\
\text { Dermatomiosite/Polimiosite. }\end{array}$ \\
\hline $\begin{array}{c}06 / 08 / 2019 \\
a \\
13 / 08 / 2019\end{array}$ & $\begin{array}{l}\text { Seminário } \\
\text { virtual sobre } \\
\text { Polimiosite/ } \\
\text { Dermatomiosite }\end{array}$ & A distância & $\begin{array}{l}\text { Desenvolvimento do seminário do grupo } 1 \\
\text { no Fórum do Moodle por meio de } \\
\text { discussões geradas pelos materiais } \\
\text { disponibilizados: slides, texto, mapa } \\
\text { mental, vídeo com relato de paciente, vídeo } \\
\text { autoral (seu diferencial), casos clínicos e } \\
\text { questionário. Troca de e-mails entre os } \\
\text { seminaristas e a professora sobre sugestão } \\
\text { de interatividade e dúvidas sobre } \\
\text { preenchimento das rubricas de avaliação } \\
\text { (critérios que orientam os alunos a } \\
\text { assumirem a responsabilidade sobre sua } \\
\text { própria aprendizagem). }\end{array}$ \\
\hline $12 / 08 / 2019$ & $\begin{array}{l}\text { Esclarecimento } \\
\text { das dúvidas do } \\
\text { grupo } 2\end{array}$ & Presencial & $\begin{array}{l}\text { Em uma sala vaga da universidade foram } \\
\text { tiradas antecipadamente (em virtude da } \\
\text { paralisação da educação) as dúvidas } \\
\text { técnicas e pedagógicas do grupo } 2\end{array}$ \\
\hline 13/08/2019 & $\begin{array}{l}\text { Congratulações } \\
\text { ao grupo } 1 \mathrm{e} \\
\text { sugestões aos } \\
\text { demais } \\
\text { seminaristas } \\
\end{array}$ & A distância & $\begin{array}{l}\text { Em virtude da paralisação, foi enviado, } \\
\text { pela manhã, um e-mail para a turma } \\
\text { congratulando o grupo } 1 \text {, dando sugestões } \\
\text { aos demais seminaristas e desejando bom } \\
\text { seminário ao grupo } 2 \text {. }\end{array}$ \\
\hline $\begin{array}{c}13 / 08 / 2019 \\
a \\
20 / 08 / 2019\end{array}$ & $\begin{array}{l}\text { Seminário } \\
\text { virtual sobre } \\
\text { Lúpus } \\
\text { Eritematoso } \\
\text { Sistêmico (LES) }\end{array}$ & A distância & $\begin{array}{l}\text { Desenvolvimento do seminário do grupo } 2 \text { no } \\
\text { Fórum do Moodle por meio de discussões } \\
\text { geradas pelos materiais disponibilizados: } \\
\text { slides, texto, vídeo autoral, caso clínico, cordel } \\
\text { (seu diferencial) e questionário. Troca de e- } \\
\text { mails entre os seminaristas e a professora } \\
\text { sobre o desenvolvimento das apresentações. }\end{array}$ \\
\hline
\end{tabular}




\begin{tabular}{|c|c|c|c|}
\hline 20/08/2019 & $\begin{array}{l}\text { Explanação de } \\
\text { assunto e } \\
\text { considerações } \\
\text { sobre os } \\
\text { seminários. }\end{array}$ & Presencial & $\begin{array}{l}\text { Explanações sobre Ciclo Celular e Meiose e } \\
\text { ao final da aula congratulações ao grupo } 2 \\
\text { e esclarecimento das dúvidas pedagógicas } \\
\text { do grupo } 3 \text {. }\end{array}$ \\
\hline $\begin{array}{c}20 / 08 / 2019 \\
a \\
27 / 08 / 2019\end{array}$ & $\begin{array}{l}\text { Seminário } \\
\text { virtual sobre } \\
\text { Esclerose } \\
\text { Sistêmica }\end{array}$ & A distância & $\begin{array}{l}\text { Desenvolvimento do seminário do grupo } 3 \\
\text { no Fórum do Moodle por meio de } \\
\text { discussões geradas pelos materiais } \\
\text { disponibilizados: slides, texto, mapa } \\
\text { mental, vídeo com relatos de pacientes, } \\
\text { caso clínico destrinchado, fórum das } \\
\text { enquetes (seu diferencial) e questionário. }\end{array}$ \\
\hline $28 / 08 / 2019$ & $\begin{array}{l}\text { Explanação de } \\
\text { assunto e } \\
\text { considerações } \\
\text { sobre os } \\
\text { seminários. }\end{array}$ & Presencial & $\begin{array}{l}\text { As explanações sobre Núcleo e Citoesqueleto, } \\
\text { em virtude do feriado municipal, aconteceram } \\
\text { no dia } 28 / 08 \text {. Ao final da aula foram dadas as } \\
\text { congratulações ao grupo } 3 \text { e foram } \\
\text { esclarecidas as dúvidas técnicas e pedagógicas } \\
\text { do grupo } 4 \text {, que no dia anterior iniciou sua } \\
\text { apresentação sobre a Síndrome de Sharp. }\end{array}$ \\
\hline $\begin{array}{c}28 / 08 / 2019 \\
a \\
04 / 09 / 2019\end{array}$ & $\begin{array}{l}\text { Seminário } \\
\text { virtual sobre } \\
\text { Síndrome de } \\
\text { Sharp }\end{array}$ & A distância & $\begin{array}{l}\text { Desenvolvimento do seminário do grupo } 4 \\
\text { no Fórum do Moodle por meio de } \\
\text { discussões geradas pelos materiais } \\
\text { disponibilizados: slides, texto, mapa } \\
\text { mental, vídeo com relato de paciente, caso } \\
\text { clínico com ferramenta e tirinhas, caça- } \\
\text { palavras e passatempo (seu diferencial). } \\
\text { Em virtude de problemas para acessar a } \\
\text { sala virtual, o grupo ganhou mais um dia } \\
\text { de docência online. Troca de e-mails entre } \\
\text { os seminaristas e a professora sobre } \\
\text { sugestão de interatividade. }\end{array}$ \\
\hline 03/09/2019 & $\begin{array}{l}1^{\mathrm{a}} \text { Avaliação } \\
\text { Teórica da } 3^{\mathrm{a}} \\
\text { Unidade }\end{array}$ & Presencial & $\begin{array}{l}\text { Antes da avaliação foram dadas as } \\
\text { congratulações ao grupo } 4 \text {. O grupo } 5 \text { não } \\
\text { apresentou dúvidas. A avaliação versou } \\
\text { apenas sobre os conteúdos de BCM. }\end{array}$ \\
\hline $\begin{array}{c}03 / 09 / 2019 \\
a \\
09 / 09 / 2019\end{array}$ & $\begin{array}{l}\text { Seminário virtual } \\
\text { sobre } \\
\text { Osteogênese } \\
\text { Imperfeita }\end{array}$ & A distância & $\begin{array}{l}\text { Desenvolvimento do seminário do grupo } 5 \text { no } \\
\text { Fórum do Moodle por meio de discussões } \\
\text { geradas pelos materiais disponibilizados: } \\
\text { slides, texto, mapa mental, vídeos com relatos } \\
\text { de pacientes reais ou fictícios (da série A } \\
\text { anatomia de Grey), vídeo autoral, caso clínico, } \\
\text { fórum de perguntas, questionário e roda de } \\
\text { conversa (seu diferencial). }\end{array}$ \\
\hline 10/09/2019 & Grupo Focal & Presencial & $\begin{array}{l}\text { Formação de grupo focal com um } \\
\text { representante de cada equipe do seminário } \\
\text { virtual assíncrono para discutir a } \\
\text { experiência híbrida vivenciada. }\end{array}$ \\
\hline
\end{tabular}

Fonte: Adaptado de Félix (2020)

No dia seguinte ao encerramento dessa intervenção, foi proposto, numa sala reservada da IES, um Grupo Focal com os estudantes. O grupo focal corresponde a uma técnica de pesquisa, na qual um determinado 
número de pessoas, selecionadas e reunidas por pesquisadores, discutem e comentam, a partir de um roteiro prévio, um tema que tanto é fruto de uma experiência pessoal como é objeto de pesquisa.

Essa técnica tem por objetivo captar, por meio das trocas realizadas no grupo, conceitos, sentimentos, atitudes, crenças, experiências e reações que poderiam ser difíceis de se manifestar por meio de outros métodos (GATTI, 2012). Pode-se dizer que a coleta de dados obtida por meio do grupo focal, registrada via Smartphone e posteriormente transcrita, nos possibilitou ter uma visão se não total, mas o mais abrangente possível dos seminários virtuais realizados, como pode ser observado melhor na seção seguinte.

\section{Resultados e discussões: análise do estudo de caso}

Os dados coletados por meio do grupo focal acerca dos seminários virtuais assíncronos foram submetidos a análise de conteúdo. De acordo com Bardin (2016), a análise de conteúdo consiste em um conjunto de técnicas de análise das comunicações, que pode ser organizado em três polos cronológicos: a pré-análise, a exploração do material e o tratamento dos resultados, a inferência e a interpretação.

Fazendo uso dessa técnica, a princípio conseguimos elucidar algumas dúvidas que surgiram durante o desenvolvimento dos seminários virtuais e que foram questionadas durante o grupo focal, como por exemplo: Por que as equipes, de um modo geral, fragmentaram tanto os fóruns? Por que todas as equipes propuseram tantas atividades, quando foi recomendada várias vezes apenas uma? Por que os grupos, sem exceção, propuseram casos clínicos como atividade? Por que os seminários virtuais, apesar de se mostrarem uma estratégia didática instigante, foram cansativos?

Segundo os alunos - identificados como RG1 (Representante do Grupo 1), RG2 (Representante do Grupo 2) e, assim, sucessivamente - a fragmentação do fórum em vários tópicos se deu por dois motivos: 1 . Não ficou claro na oficina presencial que não era para abrir tópicos; e 2. O formato do Moodle confunde o usuário: 
"Porque assim, acho que não ficou bem claro para o grupo 1 que, depois a senhora explicou, seria para não abrir tópicos, manter a discussão em um único fórum. Eu até tentei fazer esse troção, mas não ficou muito claro para todo mundo que fizesse só isso”. RG3

"Porque o Moodle é um pouco desorganizado. E quando eu clicava para responder alguma coisa, ficava caso clínico para cá, não sei o que para cá, e aquilo, outra coisa. A pessoa fica voando, sem saber para onde vai”. RG3.

No que tange a proposição de tantas atividades, em especial de caso clínico, isso aconteceu porque os estudantes se pautaram muito pelo que o grupo 1 executou e porque fica mais fácil de compreender o conteúdo, além de chamar a atenção, como podemos verificar pelo seguinte comentário:

"Eu acho que o primeiro grupo foi uma tarefa bastante dificil, mas que diante do grupo dele foi possível organizar todos os outros. Acredito nisso .... Acho que o embasamento que a gente teve primeiro para postar foi com o grupo 1. Acho de extrema importância ressaltar isso, que o grupo 1 foi primordial para o meu grupo .... Então foi primordial, RG1, o primeiro grupo para que eu pudesse entender que o caso clínico ele era importante, que a pessoa ia compreender melhor, ia buscar”. RG3.

Tal fala deixa evidente que, ao propor uma estratégia como esta, o mediador precisa ficar atento a todos os grupos, em especial ao primeiro, que inevitavelmente será o referencial para os demais.

Com relação ao fato de os seminários virtuais terem se mostrado instigantes, mas cansativos, isso aconteceu por conta de um entendimento equivocado. Os participantes dessa proposta metodológica híbrida acharam que precisavam entrar na sala de aula virtual todos os dias durante cada seminário, quando, na verdade, poderiam entrar qualquer dia, no horário que lhe fosse mais aprazível, para emitir sua opinião, argumentar, contraargumentar e tirar dúvidas, como é possível constatar pela seguinte fala:

"Ser todos os dias, porque ficou muito cansativo. Se fosse um dia, tipo, no sábado, e a gente deixasse livre para você responder em qualquer horário o trabalho, poderia ser mais proveitoso, do que todos os dias”. RG4. 
Além desses esclarecimentos imediatistas, os dados obtidos no grupo focal nos permitiram identificar as seguintes categorias: Potencialidades e Fragilidades dos Seminários Virtuais; Facilidades e Dificuldades no uso do Moodle e Ideal de Oficina, obtidas a partir da frequência com que os temas emergiam nos depoimentos.

No que tange as potencialidades, a maior contribuição dos seminários virtuais foi instigar o protagonismo dos estudantes no seu processo de aprendizagem. Ao possibilitar que o aluno alternasse momentos de docência e discência online, propiciamos a ele assumir-se como um ser autônomo, isto é, "como um ser social e histórico, como ser pensante, comunicante, transformador, criador, realizador de sonhos, capaz de ter raiva porque capaz de amar (FREIRE, 2000, p. 46).

Tal condição o estimulou a pesquisar em diversas fontes, revisar, correlacionar os materiais, indo além do que o tema propunha para torná-lo compreensível para si e para os outros, bem como lhe deu oportunidade de se expressar, de se mostrar e interagir uns com os outros e com a professora, que também corresponde a lógica comunicacional da Educação online (SILVA, 2010), como pode ser verificado pelas seguintes falas:

“...fui pesquisar ...no YouTube...no Google acadêmico...no Scielo...tomei pé da situação” RG1.4

"Ir além do que só o que o tema propõe... Além de se organizar, buscar outras informações para tornar aquilo mais acessível” RG5

“...o fórum me possibilitou, deu voz a uma pessoa que, tipo, tem vergonha de falar .... Eu tenho uma dificuldade de falar em público por conta de um trauma" RG4

“...cada um pode mostrar a sua personalidade ...pessoas... Tímidas na aula ... pode se expressar de alguma forma” RG5

"Pessoas da turma que não conseguem se manifestar na aula para tirar uma dúvida, ali fica bem mais fácil, ninguém estava olhando olho a olho...mais fácil pra... elogiar alguém, que às vezes é uma tarefa difícil” RG3 
"Promoveu essa interação ...que a gente não tem na aula... lá não tinha essa questão de autoridade, professor sobre aluno, mas sim uma troca e uma mediação de conhecimentos" RG3

Como as equipes tiveram que desenvolver seus temas de forma integrada com as tecnologias, tal fato tanto aguçou a criatividade delas, característica que corresponde a um dos princípios das TDIC como estimulou/reforçou o querer ser professor e pesquisador paralelamente ao exercício da enfermagem, reflexo de uma aprendizagem personalizada (BACICH; MORAN, 2018), como se pode observar a partir das falas abaixo:

“...o seminário... na parte de produção do conhecimento... foi uma base bem legal...só incentivou mais .... Eu quero ser professor” RG1

"Esse trabalho mostrou ... uma perspectiva de diálogo, de apresentação, de aprendizado, de uma conjuntura diferente que eu...gostei muito. Também fortaleceu muito o meu lado nessa questão de docência e, principalmente, porque eu, não é que eu tenha o sonho de ser professora, eu tenho, na verdade, o sonho de ser pesquisadora.... É, eu gosto muito dessa área. Eu quero ser pesquisadora e trabalhar na assistência hospitalar. Então, é, fermentou muito isso por causa dos casos clínicos. Eu sou muito fissurada nessas coisas. É isso. Aumentou à vontade em mim de descobrir coisas novas... novas formas de aprendizado, descobrir novos olhares” RG2

"Sim...promoveu criatividade, se colocar no lugar do outro e reforçou quanto a questão da organização" RG4

No intuito de chamar a atenção, de atender a todos os públicos (ou pelo menos a maioria) e promover interatividade (ou pelo menos alguma participação dos alunos), cada grupo disponibilizou materiais diversos no fórum: slides, resumos, vídeos, mapas mentais, enquetes, roda de conversa, caça-palavras, cordel e casos clínicos, explorando as interfaces do Moodle, de modo a potencializar a comunicação e a aprendizagem, características de uma educação cidadã e imersa na cibercultura (SILVA, 2010).

No quesito avaliação, ao incluirmos a autoavaliação vinculada ao estímulo da corresponsabilidade, quisemos que os participantes percebessem 
e avaliassem sua própria aprendizagem e a dos demais para que tivessem mais autonomia e pudessem desenvolver suas habilidades como pesquisador. De um modo geral, os estudantes avaliaram pautando-se no que rege a educação em rede, ou seja, a qualidade das colocações geradas no fórum, como podemos observar pela seguinte expressão:

“Em relação a avaliar...o critério... resposta bem elaborada... interação era muito importante... a gente mandava e as pessoas não correspondiam ou às vezes respondiam, tipo, muito superficial... analisar como...a pessoa estava se aprofundando... olhei como eles botaram, se eles facilitaram a nossa vida, tipo, dividindo em tópicos. Se botam referência” RG4

Os seminários virtuais também favoreceram a criação de um ambiente mais compreensivo e colaborativo, como podemos constatar pelas frases abaixo:

"Uma dificuldade também...uso da plataforma...sou lerda para mexer em qualquer coisa de internet...acho que dos cinco...foi o grupo que menos postou coisa mais interativa” RG2

“... a gente teve muita dificuldade com a tecnologia em si, mas tiveram pessoas que se predisporam a ajudar...gravaram vídeos explicando" RG2

Tais dificuldades evidenciam que as políticas de integração das TDIC nas atividades escolares ainda são insatisfatórias (ALMEIDA, 2010b; VALENTE; ALMEIDA, 1997) e desiguais entre as instituições de ensino de uma mesma região (ALMEIDA; ASSIS, 2011).

A nível intergrupos, pode-se dizer que muitos alunos participaram dos seminários virtuais. Apesar dessa participação não ter sido constante e nem sempre aprofundada, houve interação, troca de informações, resolução de atividades e aprendizagem, não restrita ao tema que estava sendo abordado, mas em relação a própria enfermagem, a didática que estava sendo apresentada e em relação aos recursos disponibilizados, próprios de uma educação cidadã e imersa na cibercultura (SILVA, 2010), como podemos perceber a partir dos seguintes comentários:

“A possibilidade que dá de interação.... Você passando uma informação para alguém, você aprende mais” RG4 
“...do meu grupo para lá que deu para entender mais a questão da humanização como profissional...ressaltei muito isso depois que vi os relatos de caso que colocaram que a nossa humanização como profissional era superimportante, principalmente, porque a enfermagem está super ligada a essa questão" RG3

"Proporcionou .... Essa facilidade de você entender o que você aprende... as pessoas ali procuraram seu método, do jeito que entendeu... colocar o máximo possivel de coisas. ...para que as pessoas pudessem entender da maneira mais dinâmica possivel... aprender ...da forma que elas se mais adaptassem" RG3

Os seminários virtuais por serem assíncronos e terem duração de uma semana para apresentação de cada equipe, possibilitou aos alunos, como verificamos nas falas abaixo, um tempo razoável para acessar os conteúdos disponibilizados e na hora que fosse mais favorável para eles, uma flexibilidade só possível por meio de um ensino híbrido (BACICH; MORAN, 2018):

"Uma didática que você está ali, no tempo que você pode, de onde você pode para poder entender o conteúdo" RG3

"Fica mais fácil de você poder lê, quando você está mais descansado, quando você está com mais tempo livre para você estudar" RG5

A estratégia didática integrada às TDIC também promoveu nos estudantes o desenvolvimento de uma competência típica do ensino híbrido, a autoavaliativa, haja vista que alguns alunos perceberam a importância do planejamento e da organização para se concretizar objetivos (BARBOSA, 2016); outros passaram a estudar previamente os conteúdos para assistirem as aulas e começaram a tomar nota do que o professor falava em sala de aula, elaborando mapas mentais no decorrer da aula e criando grupos de WhatsApp individuais para encaminhar os materiais disponibilizados pelos docentes da instituição, como fica evidente pelas falas abaixo:

"Sim, mudou, mas não a mesma mudança...percebi hábitos.... Eu não estudava antes de vir para a aula.... Agora não. Eu estudo antes em casa para vir para a aula.... Às vezes eu até debato com o professor ...antes as pessoas do meu 
grupo não anotavam o que o professor falava ..., mas agora percebi que na aula todos digitam...fez o mapa mental na hora todo bonitinho ou foi fluxograma” RG1

“...os meus colegas...começaram a adotar métodos de organização e planejamento depois do seminário.... Fizeram grupos individuais de Whatsapp para eles mesmo para poder postar, colocar os materiais...fazer o cronograma do dia do que é que vai fazer” RG3

“...esse trabalho...me amadureceu mais...eu já vinha tentando ser organizada..., mas provou que tem que ser assim” RG5

Ademais, alguns estudantes acharam essa metodologia de ensino melhor do que aula "normal”, como é possível apreender das seguintes falas:

“...achei que foi melhor até que aula normal.... Otimiza tempo e é bem melhor" RG3

“...gosto dessa didática pelo fato de ter uma semana para eu ter acesso a esses assuntos ...na sala de aula, a gente não consegue pegar todas essas informações necessárias” RG5

"Eu venho para uma aula, mas para mim eu me sinto meio perdido. Porque eu escuto, vejo, mas não entendo” RG3

“...na aula eu não pergunto mais do que três vezes... O professor já passa muito tempo dando aula... às vezes com muito barulho e eu parando... atrasa assunto, a aula acaba terminando mais tarde e o pessoal conversa mais e acaba embaralhando tudo" RG3

“... na sala de aula você tem que dar a sua aula, da melhor forma possível. Mas tem gente que não vai nem escutar porque não se adapta a esse método” RG5

Tais falas reforçam a necessidade de diversificar as estratégias de ensino, mas principalmente a importância de propor aulas presenciais mais significativas para os alunos, seja valorizando a relação interpessoal do grupo, seja realizando atividades que proporcionem um processo de ensinoaprendizagem mais humano, interessante e genuíno.

Entretanto, apesar das contribuições decorrentes dos seminários virtuais, existiram fragilidades diversas. Contudo, a mais emblemática 
delas, diz respeito a relevância que os sujeitos depositam na prova escrita, nas aulas tradicionais e na hierarquização do currículo. Com relação a este último aspecto, podemos dizer que o tratamento dispensado a disciplina de Anatomia é supervalorizado em detrimento de Histologia. Por exemplo, ao invés de conciliar o estudo para a prova de Anatomia com a participação nos seminários virtuais assíncronos, alguns alunos, conscientemente, dedicamse integralmente para a referida prova, haja vista que socialmente ela é considerada mais importante do que os seminários virtuais, como pode ser verificado a partir dos comentários abaixo:

“...não sei se porque esse mês tinha prova, mas... acho que falta de interesse também...um dos principais problemas que a gente teve... E o que senti falta também foi por falta de familiarização com o Moodle. Primeiro grupo foi a resposta. Eu fiz algumas perguntas e nunca responderam” RG3

“...como as doenças são raras, eu não me interessei tanto.... Se fosse...diabetes, um ataque cardiaco...instigaria mais a minha pessoa. Mas como a doenças é rara, possivelmente eu não vou nem ver” RG1

“...houveram muitos palpiteiros, mas na hora de fazer... não fazia” $R G 2$

“...dava para ver que foi muito mal feito porque foi falta de interesse $R G 4$

“...muita gente só visou a nota...isso foi meio que desmotivando a gente” RG4

Observa-se nas falas desses sujeitos a enunciação de uma suposta falta de interesse de seus colegas. Porém, percebemos a situação por um outro prisma. Os alunos estavam interessados nos seminários virtuais, mas tiveram que priorizar a prova de Anatomia porque, institucionalmente, ela tem uma relevância curricular maior do que a proposta metodológica híbrida que estávamos desenvolvendo com eles. Esta foi vista desde a sua origem como algo a mais e não como algo integrado ao currículo, como a prova de Anatomia, até mesmo de Histologia, do contrário, não tinham pedido para a atividade valer como extra. 
A disciplina de Histologia é significada pelos sujeitos como de menor importância em relação a de Anatomia. Em virtude disso, alguns alunos não participaram adequadamente dos seminários virtuais porque estavam estudando para a prova Anatomia ou porque estavam desmotivados pelo resultado negativo nela. Essa hierarquização das disciplinas que compõem um currículo precisa ser repensada porque "afoga a liberdade do educando, amesquinhando o seu direito de estar sendo curioso e inquieto" (FREIRE, 2000, p. 66-67).

O fato do aluno não se interessar tanto pelos temas dos seminários virtuais porque estes não seriam facilmente verificados no seu dia a dia, chama a atenção para a importância de se fazer uma sondagem prévia de conteúdos junto ao corpo discente durante o planejamento de uma atividade como a que está sendo discutida aqui, para instigar mais e melhor a participação dos estudantes. Ou ainda, propiciar outras atividades na disciplina de Histologia, especialmente que consiga articular a teoria com a prática para que possa propiciar ao educando uma autonomia para além dos muros da universidade.

No mais, as dificuldades giraram em torno de não ter computador pessoal, ter problema com o celular no período dos seminários, falta de acesso à internet fora das dependências da IES e dificuldade de uso da plataforma, como é possível constatar pelas falas abaixo:

“... acabei deixando mais de participar porque tive problemas com telefone, computador” RG4

“... eles disseram que não tinham, tipo, muito com essa tecnologia e alguns como iam de interior e voltava, ficava complicado ter acesso à internet nos horários que a gente queria” RG3

"Dificuldade... no meu grupo de mexer em qualquer coisa tecnológica ...acarretava que sobrava para uma única pessoa” RG4

Tais falas nos reportam novamente a questão dos investimentos insatisfatórios do Brasil em políticas públicas que garantam a integração das TDIC nos espaços educacionais, bem como as condições mínimas necessárias para explorar as potencialidades do ciberespaço, como acesso à 
internet, que representa a base da comunicação na era da mobilidade (ALMEIDA; ASSIS, 2011; PELLANDA, 2009).

No que diz respeito ao AVA Moodle, uma de suas grandes contribuições foi possibilitar a exploração de um mesmo tema de várias formas para vários públicos e ao mesmo tempo, como podemos verificar no comentário a seguir:

“... explicar de várias formas a mesma coisa... Vai atender um maior público" RG5

Outro ponto favorável da plataforma são os seus recursos. O Fórum, por exemplo, quando bem explorado, contribui para uma maior interação e troca de saberes entre alunos e destes com a professora, que é a proposta da Educação online (SILVA, 2010), como é possível deduzir à luz dos seguintes comentários:

"Se todos os professores adotassem, eu acredito que seria uma ferramenta perfeita pra dúvidas e para que a gente pudesse ter mais aquela interação com o professor” RG3

"Moodle...promoveu ...nossa autonomia em querer buscar e querer compartilhar com os outros aquilo que a gente sabe” RG3

Contudo, os alunos acharam o Moodle, de um modo geral, complicado. Em virtude disso, taxaram a plataforma de chata, desorganizada e feia, preferindo o Google Sala de Aula, como podemos constatar pelas seguintes falas:

“...o Moodle é um pouco desorganizado...A pessoa fica voando, sem saber para onde vai" RG3

"Moodle...é uma plataforma meio complicada"RG2

"Moodle é feio... é uma plataforma legal, mas precisava ser melhorado...Google sala de aula é uma ferramenta melhor ... mais organizada, mais bonita de se ver e se trabalhar" RG3

Por fim, os educandos alegaram que, apesar do tutorial com a parte prática da oficina estar explicativo, o ideal teria sido explicar esse processo no modo gravar tela do computador ou, então, que o workshop tivesse acontecido apenas com um representante de cada grupo no laboratório ou numa sala com acesso à internet. Tal movimento favoreceria a socialização das informações 
teóricas com mais clareza, seria possível acessar o Moodle e mostrar, na prática, o que precisaria ser feito. Isso pode ser percebido a partir das seguintes falas:

“... gravar tela, passo a passo” RG1

“... sugiro ... acessar o Moodle e dizer olha aqui faz isso e tal” RG3

"Teria sido mais eficaz se... pegasse um representante de cada grupo ou levasse no laboratório...e fizesse essa oficina com eles e eles depois passavam para os demais" RG3

As falas revelam que a teoria precisa estar articulada com a prática e que essa articulação precisa ser mais dialogada para envolver mais o aluno. Ou seja, quando faltou conectividade na sala de aula durante a oficina, deveríamos ter promovido um outro momento, presencial ou virtual síncrono (de resposta imediata), para desmistificar de forma mais assertiva possíveis dificuldades que fossem surgindo mediante a falta de familiaridade com o Moodle.

\section{Considerações finais}

Pode-se dizer que a estratégia didática de ensino híbrido, baseada em seminários virtuais assíncronos, trouxe contribuições diversas. No que tange aos discentes, pode-se dizer que instituiu bons hábitos (estudo prévio antes da aula, métodos de organização e planejamento), consolidou teorias (planejamento e organização permitem concretização de objetivos), instigou desejos (ser professor/a, pesquisador/a) e promoveu o protagonismo discente, uma vez que houve o desenvolvimento de sua capacidade autônoma, estímulo à sua criatividade, incentivo a pesquisa, interação e colaboração em sala de aula.

Os estudantes também apontaram que a oficina teria sido mais proficua se tivesse sido realizada apenas com um representante de cada equipe, num local com acesso à internet para ir executando junto com eles o que precisava ser realizado na qualidade de docente online, ou então realizar o processo no modo gravar tela do computador e disponibilizar para todos. Da mesma forma, 
alegaram que o Moodle é uma plataforma complicada, preferindo, assim, o Google Sala de Aula, por ser mais organizado, acessível e de design mais aprazível.

De um modo geral, pode-se dizer que os seminários virtuais, apesar de propiciarem uma experiência libertadora aos estudantes, foi percebido desde a sua gênese como um algo a mais e não como uma atividade integrada ao currículo. Tanto foi assim que alguns alunos ao invés de conciliar sua participação nos seminários virtuais assíncronos com as provas de Anatomia e de Histologia, optavam conscientemente pela prova, especialmente da primeira disciplina por ser eleita a mais importante do currículo, em detrimento da proposta metodológica híbrida desenvolvida junto a eles.

Por fim, evidencia-se que, para propor uma metodologia ativa e híbrida, e promover Educação online é preciso uma mudança de postura docente e também discente, mas principalmente uma ressignificação do currículo, pois uma disciplina não pode ser supervalorizada em detrimento de outras, pois todas são necessárias a formação do indivíduo, da mesma forma que são essenciais maiores investimentos em políticas públicas que ampliem o acesso da população às tecnologias digitais em rede e que insira os (as) professores (as), desde a sua formação inicial, em práticas pedagógicas ativas e inseridas na cibercultura.

\section{Referências}

ALMEIDA, Maria Elizabeth B. de; SILVA, Maria da Graça Moreira da. CURRÍCULO, TECNOLOGIA E CULTURA DIGITAL: ESPAÇOS E TEMPOS DE WEB CURRÍCULO. Revista e-curriculum, São Paulo, v.7 n.1 Abril/2011. Disponível em: http://revistas.pucsp.br/index.php/curriculum/article/viewFile/5676/4002. Acesso: 12 jan. 2020.

ALMEIDA, Maria Elizabeth Bianconcini. Integração de Tecnologias na Educação Pública do Brasil e de Portugal. I Encontro Internacional TIC e Educação - ticEDUCA2010. Portugal: Universidade de Lisboa, 2010b.

ALMEIDA, Elizabeth Bianconcini de; ASSIS, Maria Paulina de. Integração da web 2.0 ao currículo: a geração web currículo. Organización de los Estados Americanos: Revista digital la educ@cion, 2011. Disponível em: https://paulassis.files.wordpress.com/2011/04/integrac3a7c3a3o-da-web-2-0-aocurrc3adculo-a-gerac3a7c3a3o-web-currc3adculo.pdf. Acesso: 12 jan. 2020. 
AMEM, Bernadete Malmegrim Vanzella; NUNES, Lena Cardoso. Tecnologias de informação e comunicação: contribuições para o processo interdisciplinar no ensino superior. Revista Brasileira de Educação Médica, Rio de Janeiro, v. 30, n. 3, p. 171-180, 2006. Disponível em: http://www.scielo.br/pdf/rbem/v30n3/07.pdf. Acesso: 10 mar. 2018.

ANASTASIOU, Léa das Graças Camargos; ALVES, Leonir Pessate. (Orgs). Processos de ensinagem na universidade: pressupostos para as estratégias de trabalho docente em aula. 6. ed. Joinville: Univille, 2006.

BACICH, Lilian; MORAN, José (ORGS.). Metodologias ativas para uma educação inovadora: uma abordagem teórico-prática. Porto Alegre: Penso, 2018.

BARBOSA, Renata Cristina. Avaliação, tecnologia e ensino híbrido. Revista Linha Direta, 2016. Disponível em:

https://www.portalinhadireta.com.br/publico/images/pilares/616f72c1eb9f3e7c3d5e 16705bfc5f1f.pdf. Acesso em: 12 jan. 2020.

BARDIN, Laurence. Análise de conteúdo. São Paulo: Edições 70, 2016.

BRANSKI, Regina Meyer et al. METODOLOGIA DE ESTUDO DE CASOS APLICADA À LOGÍSTICA. XXIV ANPET Congresso de Pesquisa e Ensino em Transporte. Brasil, Salvador, janeiro de 2010. Disponível em: https://www.researchgate.net/publication/277598822_METODOLOGIA_DE_E STUDO_DE_CASOS_APLICADA_A_LOGISTICA. Acesso em: 05 set. 2020.

CECCIM, Ricardo Burg; FEUERWERKER, Laura Macruz. Mudança na graduação das profissões de saúde sob o eixo da integralidade. Cadernos de Saúde Pública, Rio de Janeiro, v. 20, n. 5, p. 1400-1410, set-out. 2004.

CHRISTENSEN, Clayton; HORN, Michael e STAKER, Heather. Ensino Hibrido: uma Inovação Disruptiva? Uma introdução à teoria dos híbridos. Maio de 2013. Disponível em: https://www.pucpr.br/wp-content/uploads/2017/10/ensinohibrido_uma-inovacao-disruptiva.pdf. Acesso: 03 ago 2019.

EISENHARDT, K.M. (1989) Building theories form case study research. Academy of Management Review. New York, New York, v. 14 n. 4.

FREIRE, Paulo. Pedagogia da autonomia: saberes necessários à prática educativa. 50. ed. Rio de Janeiro: Paz e Terra, 2000. 165p.

FÉLIX, Viviane Patrícia Pereira. Seminários virtuais assíncrono de histologia: análise de uma pesquisa-formação em um curso superior de enfermagem de Alagoas. Dissertação (Mestrado em Ensino de Ciências e Matemática) Universidade Federal de Alagoas. Centro de Educação. Programa de PósGraduação em Ensino de Ciências e Matemática. Maceió, 2020. 
GATTI, Bernardete Angelina. Grupo focal na pesquisa em ciências sociais e humanas. Brasília: Liber Livro Editora, 2012.

HORN, Michael; STAKER, Heather; CHRISTENSEN, Clayton. Blended: usando a inovação disruptiva para aprimorar a educação. Penso Editora, 2016.

LARA, Rafael; QUARTIERO, Elisa Cunha. Educação para uma geração pósinternet: olhares a partir da formação inicial de professores. In: SANCHES, Jayme. Congreso Iberoamericano de Informática Educativa. Santiago, Chile, 2010.

LÉVY, Pierre. Cibercultura. $3^{\circ}$ ed. São Paulo: Editora 34, 2010.

MARTINS, Alexandra da Costa Souza; ALVES, Lucicleide Araújo de Sousa Alves. $\mathrm{O}$ fórum de discussão como instrumento avaliativo de aprendizagem. Informática na educação: Teoria \& Prática. Porto Alegre, v. 19, n. 2, jun./set. 2016.

MORAN, José. Mudando a educação com metodologias ativas. Coleção Mídias Contemporâneas. Convergências Midiáticas, Educação e Cidadania: aproximações jovens. Vol. II. Carlos Alberto de Souza e Ofelia Elisa Torres Morales (Orgs.). PG: Foca Foto-PROEX/UEPG, 2015. Disponível em: http://www2.eca.usp.br/moran/wpcontent/uploads/2013/12/mudando moran.pdf. Acesso em: 15 mar. 2019.

OLIVEIRA, Jéssica Maria; MACIEL, Marília de Holanda; SILVA, Rutt Keles Alexandre da. Metodologias Ativas: Caminhos Facilitadores da Aprendizagem Para Contribuir No Alcance Do Ods 4. Anais do $16^{\circ}$ Congresso Internacional de Tecnologia na Educação. Brasil, Recife, setembro de 2018.

RODRIGUES, E. F. A questão da verificação de aprendizagem no modelo de ensino híbrido. In: BACICH, L.; TANZI NETO, A.; TREVISANI, F. de M. (Org.). Ensino híbrido: personalização e tecnologia na educação. Porto Alegre: Penso, 2015.

SILVA, Roger Magalhães da et al. Situações-limite na formação de professores de ciências na perspectiva freireana: da percepção da realidade à dimensão pedagógica. Investigações em Ensino de Ciências - V21(3), pp. 127-151, 2016. Disponível em: https://www.if.ufrgs.br/cref/ojs/index.php/ienci/article/view/671/447. Acesso em: 02 Set 2019.

SILVA, Marco. Criar e professorar um curso online: relato de experiência. In: SILVA, Marco (Org.). Educação online. São Paulo: LOYOLA, $2^{\mathrm{a}}$ ed.: jun./2006, p. 53-75.

SILVA, Marco. Educar na cibercultura: desafios à formação de professores para docência em cursos online. Revista Digital de Tecnologias Cognitivas. São Paulo, n. 3, p. 36-51, jan./jun., 2010. 
SPINARDI, Janine Donato e BOTH, José Ivo. Blended Learning: O Ensino Híbrido e a Avaliação da Aprendizagem no Ensino Superior. Rio de Janeiro: B. Téc. Senac, v. 44, n. 1, jan./abr. 2018. Disponível em: https://www.bts.senac.br/bts/article/view/648. Acesso: 05 Jan 2019.

VALENTE, José Armando; ALMEIDA, Fernando José. Visão analítica da informática no Brasil: a questão da formação do professor. Revista Brasileira de Informática na Educação. Sociedade Brasileira de Computação, Florianópolis, n. 1, 1997. Disponível em http://www.professores.uff.br/ hjbortol/ car/library/valente.html. Acesso em: 10 mar. 2018.

VEEN, Wim; WRAKKING, Benn. Homo Zappiens: educando na era digital. Porto Alegre: Artmed, 2009.

YIN, R.K. (2009) Case study research, design and methods (applied social research methods). Thousand Oaks. California: Sage Publications.

Recebido em setembro de 2020.

Aprovado em janeiro de 2021. 